\title{
Dementia and the protective role of cognitive reserve
}

\author{
Demência e o efeito protetivo da reserva cognitiva
}

Jerson Laks La, $^{1,2}$

'Universidade Federal do Rio de
Janeiro, Intituto de Psiquiatria, Rio
de Janeiro RJ, Brazil;
${ }^{2}$ Universidade do Estado do Rio

Ditive reserve is a complex concept. In short, it states that in the presence of neural ailments, the more there is a continued mental activity across the lifespan, the more flexible will be the brain to face them. Cognitive reserve is attained by developing several behavioral and cognitive repertoires'.

It is now well established that a combination of previous intelligence level, duration of formal education, amount of leisure, of mental, and of physical activities affect the brain reserve. Therefore, cognitive reserve also influences the risk of incident dementia and the evolution of clinical stages of neurodegenerative and vascular dementias ${ }^{2}$. Not only duration of formal education, but also the quality of performance thoughout the years may have an influence on cognitive reserve and on how the person reacts to having dementia in clinical terms. School performance and grades, specially in language and mathematics skills in childhood seem to be protective of dementia risk. A small study by our group has shown that higher school performance and years of education decreased the chance of dementia by $79 \%$ (OR $=0.21$; CI $0.08-0.58)$ and $21 \%(\mathrm{OR}=0.79$; $\mathrm{CI} 0.69-0.91)$, respectively ${ }^{3}$. These facts raise the issue that education in early life should be viewed as a health issue to prevent and better manage diseases over the life course. Enhancing cognitive reserve over the life cycle may have direct economic, clinical, and terapeutic impacts on dementia management in the elderly.

The study published in this issue by Sobral, Pestana and Paúl ${ }^{4}$ adds further confirmation to the available data on how cognitive reserve may influence the outcome of Alzheimer's disease patients. The simple and straightforward methodology applied is of clinical and practical use. It also has the quality of providing an update on the subject, drawing attention to what can be done to enhance the protective measures to deal with the devastating stages of Alzheimer's disease, still with no foreseeable cure in the near future.

\section{References}

1. Stern, $Y$. What is cognitive reserve? Theory and research application of the reserve concept. J Int Neuropsychol Soc. 2002;8: 448-60. http://dx.doi.org/10.1017.S1355617701020240

2. Meng X, D'Arcy C. Education and dementia in the context of the cognitive reserve hypothesis: a systematic review with meta-analyses and qualitative analyses. PLoS One. 2012;7(6):e38268. http://dx.doi.org/10.1371/journal.pone.0038268
3. Bezerra AB, Coutinho ES, Barca ML, Engedal K, Engelhardt E, Laks J. School attainment in childhood is an independent risk fator of dementia in late life: results from a Brazilian sample. Int Psychogeriatr. 2012;24(1):55-61. http://dx.doi.org/10.1017/S1041610211001554.

4. Sobral M, Pestana MH, Paúl C. Cognitive reserve and the severity of Alzheimer's disease. Arq Neuropsiquiatria 2015;73(6):480-6. http://dx.doi.org/10.1590/0004-282X20150044 